\title{
Figures, Tables, Boxes, and Appendices
}

\section{Figures}

1.1 Distributions of ability to read, by respondent's highest grade in school 8

1.2 Per capita GDP, 2019, selected countries in South, Southeast, and East Asia, by adult literacy rate, c. $2018 \quad 10$

1.3 Change in per capita GDP, 2000-2019, selected countries in South, Southeast, and East Asia, by adult literacy rate, c. 200012

1.4 Distributions of Rana Plaza survivors, by gender and highest education level 13

1.5 Under-five mortality rate, selected countries in South, Southeast, and East Asia, by female literacy rate, c. $2018 \quad 15$

1.6 Percentage living below lower-middle-income country poverty line (US\$3.20/day), selected countries in South, Southeast, and East Asia, c. 201616

2.1 Adjusted net enrolment rate, primary age cohort, selected years 26

2.2 Female share of enrolment, primary age cohort, selected years 27

2.3 Survival rate to final year of primary cycle, selected years

2.4 Young adult literacy rate, ages 15-24, selected years 33

2.5 Young adult literacy rate in India, Bangladesh, and Pakistan, ages 15-24, by gender, selected years 34

3.1 Sample ASER reading and mathematics cards, West Bengal 39

3.2 Percentage of students able to master ASER reading and mathematics protocol, by selected grades, India, 2008-2018

3.3 State-level ASER Grade 3 reading/mathematics score, 2018, by per capita state GDP, $2017 \quad 49$ 
3.4 State-level ASER Grade 3 reading/mathematics score, 2018, by SHD index, 201850

4.1 Percentage of Grade 5 students able to read ASER story and perform division, by school type, India, 2008-2018 57

4.2 Average young adult (ages 15-24) literacy rate, 2010-2016, by average per primary student government spending as percentage of per capita GDP, 2007-2016, selected Southeast and East Asian countries 59

4.3 Average young adult (ages 15-24) literacy rate, 2010-2016, by average country percentiles, Worldwide Governance Index, selected Asian countries, $2016 \quad 60$

4.4 Primary pupil-teacher ratio, selected Asian countries, by per capita GDP, 201761

5.1 Government spending on education, South Asian countries, 1970-2019 81

7.1 Mean national PISA reading score (2015), by median national teacher PIAAC literacy score $(2012,2014) \quad 101$

7.2 Mean national PISA mathematics score (2015), by median national teacher PIAAC numeracy score $(2012,2014) \quad 101$

7.3 Attributes of the twenty-first-century teachers in Singapore skills, knowledge, and values 112

8.1 Teacher education and professional development system in Sri Lanka 122

9.1 Career tracks for teachers in Singapore 127

11.1 Distributions of student families' food security, Bangladesh pilot study, by school type 164

11.2 Distributions of student families' socio-economic status, selected Lagos schools, by school type 167

12.1 Optimal school autonomy, given capacity of teachers and administrators 183

12.2 Distributions of responsibility for student assessment policies among agents in education system, by quarters of PISA countries ranked by overall PISA reading score, 2015184

12.3 Distributions of responsibility for school resource decisions among agents in education system, by quarters of PISA countries ranked by overall PISA reading score, 2015184

\section{Tables}

2.1 Literacy definitions and assessment method used in population censuses conducted in South Asia 30

3.1 ASER distributions of reading performance, by grade 40 
3.2 ASER distributions of mathematics performance, by grade 41

3.3 National Student Assessment, Bangladesh - overall average scores, 2011-2017 43

3.4 National Student Assessment, Bangladesh - distributions of student performance in reading and mathematics, using new "on-grade performance standards," 2015, 201744

3.5 National Student Assessment, Bangladesh - distributions of student performance in reading, Grade 3, by school type, using new "on-grade performance standards," 201744

4.1 Agents in school systems, illustrative activities 68

4.2 Percentile ranking by WGI dimensions, selected countries, 201675

6.1 Teacher workforce and student enrolment, primary and secondary schools in South Asia, c. 201794

9.1 Monthly income, entry-level government teachers, selected states and countries 136

9.2 Teacher status rank - Asian sample in Varkey Teacher Status Survey 142

10.1 Most prevalent content items related to SDG target 4.7 in 22 Asian countries reported by MGIEP Report 147

11.1 Ability to perform sample assessment items, Grade 2, by school type, in Lagos, Nigeria 168

12.1 Classification of the state government education department's functions into steering and rowing 194

\section{Boxes}

1.1 Bangladesh Garment Sector 13

2.1 EFA Goals and Strategies, Dakar Framework, 2000-2015 23

2.2 Sustainable Development Goal 425

5.1 The History of Sri Lanka's Educational Development, 1830-1948 79

5.2 Improving Pedagogy, Curriculum, Teacher Training, and Planning 85

7.1 Eligibility for Teaching in High-Performing Countries 108

9.1 Teachers' Associations and Unions in Pakistan 134

9.2 Bangladesh: Quality Education: Teachers for the Next Generation 137

9.3 Teachers' Incomes in South Asia 140

10.1 The Nine Domains of Ethics and Values Education (EVE) 149

10.2 Cognitive Dissonance 151

11.1 Abidjan Principles, 2019162 
x Figures, Tables, Boxes, and Appendices

11.2 Bridge Academies 165

11.3 Bangladesh: An Education System That Divides the Nation 175

12.1 What Is Decentralization? 189

12.2 The Ten Commandments for Education Reform 192

\section{Appendices}

3.1 EGRA and ASER 52

4.1 Governance Indices 74

11.1 The Role and Impact of Private Schools in Developing Countries: Key Findings of a Meta-Analysis 177

12.1 An Outline for Separation of Powers in Education Governance Proposed by the Centre for Civil Society, Delhi 201 